$12 / 2+9+9 x+1$

UCRL-ID-115726

\title{
Diffusion Bonding of Superplastic Aluminum Alloys
}

\author{
Anne J. Sunwoo
}

December 1993

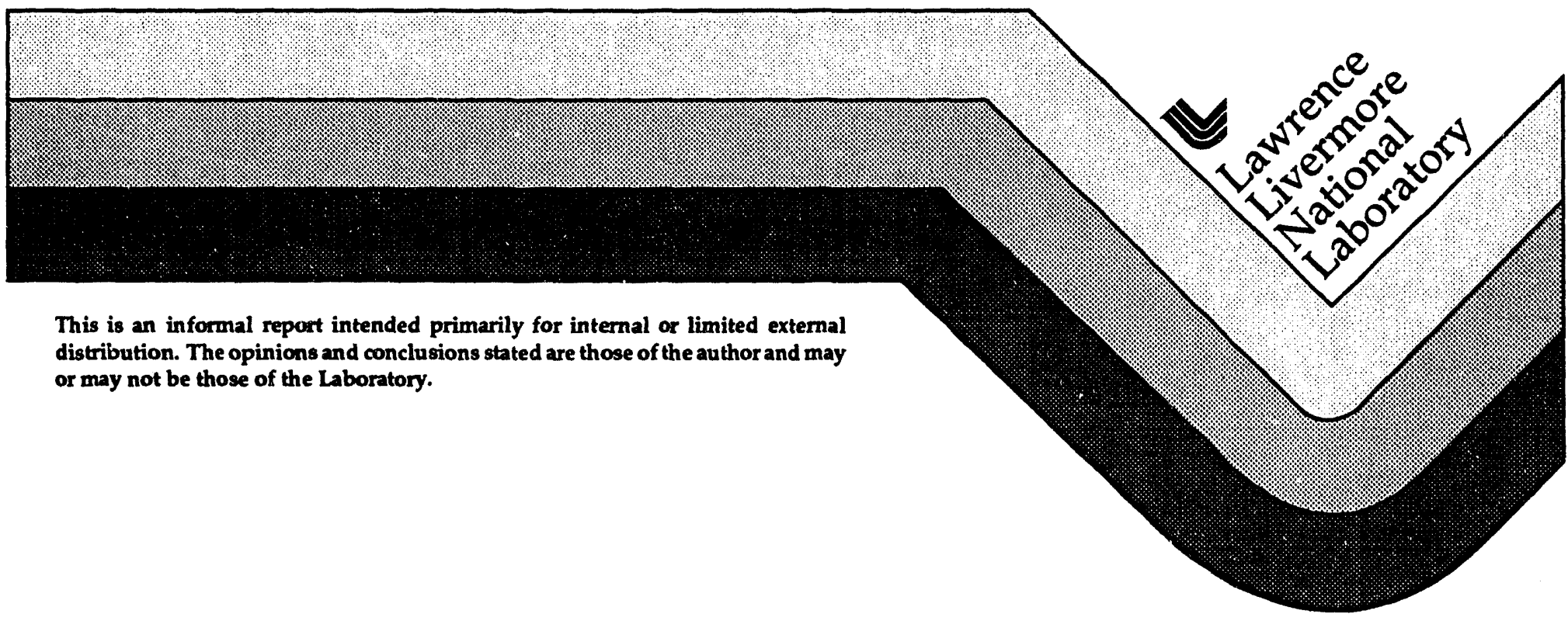




\section{DISCLAIMER}

This document was prepared as an acccount of work sponsored by an agency of the United States Government. Neither the United States Government nor the University of California nor any of their employees, makes any warranty, express or implied, or assumes any legal liability or responsibility for the accuracy, completeness, or usefulness of any information, apparatus, product, or process disclosed, or represents that its use would not infringe privately own rights. Reference herein to any specific commercial products, process, or service by trade name, trademark, manufacturer, or otherwise, does not necessarily constitute or imply its endorsement, recommendation, or favoring by the United States Government or the University of Califonia. The views and opinions of authors expressed herein do not necessarily state or reflect those of the United States Government or the University of California, and shall not be used for advertising or product endorsement purposes.

This report has been reproduced directly from the best available copy.

Available to DOE and DOE contractors from the Office of Scientific and Technical Information P.O. Box 62, Oak Ridge, TN 37831

Prices available from (615) 576-8401, FTS 626-8401

Available to the public from the National Technical Information Service

U.S. Department of Commerce 5285 Port Royal Rd., Springfield, VA 22161 


\title{
Diffusion Bonding of Superplastic Aluminum Alloys
}

\author{
Anne J. Sunwoo \\ Engineering Sciences Division, Mechanical Engineering
}

\section{Introduction}

Ability to diffusion bond aluminum alloys, in particular superplastic aluminum alloys, will complete the technology-base that is strongly needed to enhance the use of superplastic forming (SPF) technology. Concurrent diffusion bonding (DB)-SPF is considered to be an energy-saving manufacturing process since it simplifies the production of complex components. Moreover, because of increased design flexibility, overall manufacturing cost and component weight are signficantly reduced.[1]

Diffusion bonding is an attractive manufacturing option for applications where the preservation of the base metal microstructure and, in turn, mechanical properties is imperative in the bond area. The process utilizes either the solid state or transient liquid phase (TLP) bonding to produce a bond with microstructure continuity in the joint. [2,3] In addition, there is no localized thermal gradient present to induce distortion or to create residual stresses in the component, thereby increasing structural integrity.

Despite the strong interest by both the aerospace [4] and automotive [5] industries to extend this technology to aluminum (Al) alloys, technical progress in this specific area has been relatively slow. So far, only certain titanium alloys have been demonstrated to be DB-SPF.[1] The extreme difficulty associated with the $\mathrm{DB}$ of $\mathrm{Al}$ alloys is a readily formed, tenacious $\mathrm{Al}$ oxide layer. Unlike Ti alloys, the solubility of oxygen in aluminum is less than 0.01 at- $\%$ and the stability of oxide is such that it will not decompose at desired bonding temperatures, even in vacuum. The oxide layer acts as an effective barrier preventing atoms from interdiffusing across the bond interface and, consequently, yields a poor metallurgical bond. However, the aluminum-lithium alloy 8090 has exhibited successful solid state diffusion bonding by modifying the $\mathrm{Al}$ oxide to less stable, discontinuous lithium-rich $\mathrm{Li}-\mathrm{Al}$ spinels.[6] They appear as discrete, brittle particles on the bond interface. Joints that were solid state diffusion bonded in vacuum showed a planer microstructure at the interface and shear strengths similar to those of the base material. Moreover, the 8090 alloy has lower density, and higher specific strengths and modulus than the other high strength $\mathrm{Al}$ alloys, which are attractive attributes for weight-restricted aerospace applications. It is also quenchinsensitive, which reduces the possibility of distortion to fabricated DB-SPF components, [7] and can precipitate strengthening phases during cooling.

Another Al alloy that has been studied for DB is 7475 , which has high strength and good corrosion resistance. $[8,9]$ In addition, it can be thermomechanically processed to be superplastic. However, the DB successes for both 7475 and 8090 have been limited to the laboratory conditions only. As the technology moves from the laboratory to production, the DB process has to be production feasible and cost-effective.

A comparative study of the DB of SPF Al alloys has been initiated at the Lawrence Livermore National Laboratory to determine the effect of surface chemistry on the DB properties of the aluminum alloys, $8090(2.4 \mathrm{Li}-1.18 \mathrm{Cu}-0.57 \mathrm{Mg}-0.14 \mathrm{Zr}-\mathrm{Al})$ and $7475(1.26 \mathrm{Cu}-2.01 \mathrm{Mg}-5.27 \mathrm{Zn}-$ $0.17 \mathrm{Cr}-0.006 \mathrm{Si}-0.012 \mathrm{Fe}-\mathrm{Al}$ ). The integrity of the diffusion bonds was evaluated for both interlayered and bare surfaces. Two interlayer elements, copper $(\mathrm{Cu})$ and zinc $(\mathrm{Zn})$, were compared. Although the eutectic temperature of $\mathrm{Al}-\mathrm{Cu}$ is $548^{\circ} \mathrm{C}$, a thin $\mathrm{Cu}$ layer in contact with 8090 has been shown to lower its eutectic temperature to $\sim 521^{\circ} \mathrm{C}$.[6] In $8090, \mathrm{Cu}$ is one of the primary alloying elements but has a limited solubility in $\mathrm{Al}$ at the bonding temperature. Zinc, on the other hand, forms a considerably lower eutectic $\left(380^{\circ} \mathrm{C}\right)$ with $\mathrm{Al}$ and is highly soluble in $\mathrm{Al}$. In $7475, \mathrm{Zn}$ is the primary alloying element. The diffusivity of $\mathrm{Zn}$ in $\mathrm{Al}$ is much faster than that of 
$\mathrm{Cu}$, but $\mathrm{Zn}$ forms a more thermodynamically stable oxide. These subtle metallurgical differences will affect the TLP formation at the interface, which in turn will influence the bond quality.

\section{Experimental Procedure}

The as-received plates of $8090-\mathrm{T} 81$ and 7475-T6 were $9.5 \mathrm{~mm}$ and $19.0 \mathrm{~mm}$ thick, respectively, and were cut to $25.4 \mathrm{~mm} \times 25.4 \mathrm{~mm}$ samples. Plates were used to determine the bond tensile strength. The surfaces to be bonded were machined and lapped with 600 grit SiC paper. To enhance grain boundary diffusion at the bonding interface, the bonding surfaces were matched in the short-transverse orientation to take advantage of elongated grains. Figure 1 shows the microstructure of 8090 and 7475 in three orientations.

Electroplating process was used to coat $\mathrm{Cu}$ and $\mathrm{Zn}$ interlayers on the $\mathrm{Al}$ surfaces. Prior to plating, the samples were degreased in acetone and immersed in Enthone NS-35 solution for 5 min. Then 5 sides were masked. The unmasked side of the samples was again electrocleaned in Enthone solution, followed by immersing in a 50 vol.-\% nitric acid for $10 \mathrm{~min}$. To further remove any residual oxide film on the surface, the samples were again immersed in a 30 vol.-\% zincate solution containing $\mathrm{ZnO} / \mathrm{NaOH}$ for $2 \mathrm{~min}$. A $10 \mu \mathrm{m}$ thick layer of $\mathrm{Cu}$ was plated on the bonding surfaces using an Allied Kelite solution at $2.3 \mathrm{~A} / \mathrm{m}^{2}\left(25 \mathrm{~A} / \mathrm{ft}^{2}\right)$, while a $10 \mu \mathrm{m}$ thick layer of $\mathrm{Zn}$ was plated using a $\mathrm{Zn}$ cyanide bath at $1.4 \mathrm{~A} / \mathrm{m}^{2}\left(15 \mathrm{~A} / \mathrm{ft}^{2}\right)$, followed by water rinse.

The diffusion bonding apparatus consisted of two ceramic platens each $50 \mathrm{~mm}$ diameter and $150 \mathrm{~mm}$ thick, a quartz tube $63.5 \mathrm{~mm}$ diameter, weights, and a water-cooled, tubular quartz furnace. Before putting the surfaces together, the samples were again ultrasonically cleaned in ethanol and then, they were sandwiched between ceramic platens prior to placing inside the quartz tube. In the furnace, the tube was sealed and back-filled with argon and a predetermined weight, which was held in place by the movable cross-head of a test machine, was loaded on the ceramic platens. Two chromel-alumel thermocouples were used to monitor the temperature, one embedded in the sample and other near the sample for furnace temperature control.

The thermal history used for the DB of both 8090 and 7475 samples was the same. Under a static pressure, the samples were heated to $550^{\circ} \mathrm{C}$ at $18^{\circ} \mathrm{C} / \mathrm{min}$ and held for $15 \mathrm{~min}$ to ensure melting of $\mathrm{Cu}$ interlayer, lowered to $500^{\circ} \mathrm{C}$ for $60 \mathrm{~min}$, and then slowly furnace-cooled. For the 7475 samples, a higher applied pressure was used, $2.9 \mathrm{MPa}$ (420 psi), in comparison to the 8090 samples, 1.2 MPa (175 psi). The bonded interfaces and fracture surfaces were examined using optical metallography and scanning electron microscopy (SEM) fractogrphy, respectively. The bond quality was determined by tensile tests at room temperature. The specimens were pulled at a constant crosshead speed of $1.27 \mathrm{~mm} / \mathrm{min}$ with the bond located at the center of the $25.4 \mathrm{~mm}$ gage length.

\section{Results and Discussion}

\section{Diffusion Bonding of 8090}

For the bare surface DB of 8090 , the benefit of $\mathrm{Li}-\mathrm{Al}$ spinel formation at the bonding surfaces was not found. In a non-vacuum environment, the specimen simply did not bond. Although there was a sufficient pressure available to produce interfacial contact at the bonding surfaces, in an argon atmosphere with a partial pressure of oxygen, even the freshly exposed metal surfaces would reoxide and prevent the metal/metal contact required to form the bond.[10] Figure 2 shows the heavily oxidized fracture surface of DB 8090 with localized dimples suggesting an earlier presence of spinel particles.

The use of thin protective layer to prevent oxidation on the joining surfaces has been utilized in many applications in various industries. For example, in the electronic industry, maintaining the solderability of $\mathrm{Cu}$ lands on printed circuit boards is critical during component packaging.[11] To protect these $\mathrm{Cu}$ lands, a thin layer of a eutectic lead-tin solder is commonly coated on the $\mathrm{Cu}$. During packaging, the solder dissolves into the bath, providing oxide-free $\mathrm{Cu}$ surfaces to be resoldered. A similar role applies to the interlaye., which is to protect the surfaces prior to 
bonding. At the bonding temperature, melting at the interlayer interface forms a TLP. However, the desorption, transportation, and reprecipitation phenomenon that occurs at the melt region [12] will vary depending on the reaction between substrate and interlayer.

The difference in the $\mathrm{Cu}$ and $\mathrm{Zn}$ TLP formation and their effects on DB are shown in the crosssections of the polished DB joints of 8090 (Figure 3). For the $\mathrm{Cu}$ interlayer, the bond interface was difficult to detect (Figure 3a). A discrete dispersion of $\mathrm{Cu}$-rich phases near the bond area provided the only observable indication of the bond location. Three ternary intermetallic compounds that are in equilibrium with the $\mathrm{Al}$-rich solid solution are $\mathrm{T}_{\mathrm{B}}\left(\mathrm{Al}_{7.5} \mathrm{Cu}_{4} \mathrm{Li}\right), \mathrm{T}_{1}\left(\mathrm{Al}_{2} \mathrm{CuLi}\right)$, and $\mathrm{T}_{2}$ $\left(\mathrm{Al}_{2} \mathrm{CuLi}_{3}\right)$.[13] These particles were only present within $125 \mu \mathrm{m}$ from the interface. A similar observation was made by Bushby and Scott [14] where they found that $\mathrm{Cu}$ had diffused up to 150 $\mu \mathrm{m}$ into the $\mathrm{Al}$ when held at $550^{\circ} \mathrm{C}$ for $100 \mathrm{~min}$. Also note that these $\mathrm{Cu}$-rich phases did not form on all the grain boundaries. Diffusion of Cu or TLP into the base metal through the grain boundary region is strongly influenced by the grain misorientation, whether it is random (high-angle) or ordered (low-angle) boundaries.[15] In the case of the random high-angle boundaries, higher grain boundary energy promotes deeper liquid penetration and the formation of a smaller dihedral angle with the liquid phase. On the other hand, a much smaller effect of liquid penetration and change in the solid-liquid interface profile is seen with low-angle boundaries based on their lower boundary energy.

For the $\mathrm{Zn}$ interlayer specimens, the reaction at the interface was significantly different. The cross-section of the DB specimen showed more distinct outline of the bond interface (Figure $3 \mathrm{~b}$ ). Unlike $\mathrm{Cu}, \mathrm{Zn}$ does not form a common ternary intermetallic compound with any of the alloying elements in 8090 , but in contact with $\mathrm{Al}$, undergoes a phase change at $\sim 385^{\circ} \mathrm{C}$, [2] which is close to the eutectic temperature of the $\mathrm{Zn}-\mathrm{Al}$ system. As the $\mathrm{Zn}$-rich TLP dissolves rapidly into the $\mathrm{Al}$ matrix at the DB temperature, the areas with eutectic composition at the interface will be the last to solidify. Thus, the noticeable difference in composition was only seen at the bond interface of an unetched specimen. Both $\mathrm{Cu}$ and $\mathrm{Zn}$ interlayer specimens contained nonplanar interface profiles and the presence of extensive plastic deformation was evident in the grains near the interface where they were severely misaligned. Thus, the DB pressure of $1.2 \mathrm{MPa}$ used for 8090 was sufficient for intimate contact to occur at the interface.

In order to effectively compare the bond quality, the 8090 base metal was reprocessed using the DB parameters. The tensile test results are listed in Table 1. With the same interlayer thickness and bonding parameters, the tensile properties of the $\mathrm{Cu}$ interlayer specimens of both alloys were found to be substantially better than those of the $\mathrm{Zn}$ interlayer specimens. For the $\mathrm{Cu}$ interlayer 8090 specimens a joint efficiency, which is a ratio of the joint yield strength to the base metal yield strength, of $50 \%$ ( $200 \mathrm{MPa}$ ) was obtained. In comparison, only a $25 \%$ joint efficiency was obtained for the $\mathrm{Zn}$ interlayer 8090 specimens.

Figure 4 shows the fracture surfaces of the $\mathrm{Cu}$ and $\mathrm{Zn}$ interlayer specimens. The typical fracture behavior of 8090 alloy was seen in the fracture surface of a $\mathrm{Cu}$ interlayer specimen. The surface revealed ductile dimples with delamination along the grain boundaries (Figure 4a). Because the delamination occurred along the boundaries that contained $\mathrm{Cu}$-rich phases, the grains shown in the fracture surface appeared much larger than those in the $\mathrm{Zn}$ interlayer fracture surface (Figure $4 \mathrm{~b})$. In the case of the $\mathrm{Zn}$ interlayer specimens, the crack propagated along the bond interface resulting in predominately intergranular fracture with some ductile dimples. As a result, this fracture surface is more representative of the pancake-like microstructure of the base metal.

\section{Diffusion Bonding of 7475}

For the 7475 alloy, the $\mathrm{Cu}$ interlayer specimens displayed promising bond strengths of $175 \mathrm{MPa}$. The cross-section of the $\mathrm{Cu}$ interlayer specimen showed a high fraction of metal-tometal contacts, where the bond interface was not easily discerned, as indicated by the arrows in Figure 5a. However, there were enough areas with inadequate bonding to adversely influence the bond strength. In addition, a slow cooling of the specimen from the DB process resulted in the precipitation of fine $\mathrm{MgZn}_{2}$ in the matrix and $\mathrm{Al}_{2} \mathrm{CuMg}$, or $\mathrm{Al}_{7} \mathrm{Cu}_{2} \mathrm{Fe}$, at the grain boundaries.[16] 
The precipitation of grain boundary phases led to a solute-depleted, precipitate-free zone (PFZ) for the grains near the bond interface. A similar PFZ developed during SPF when diffusional creep was the dominant deformation mechanism.[17]

Diffusion bonding of 7475 with the $\mathrm{Zn}$ interlayer continued to have inadequate bond strengths where many of the specimens broke during handling. Thus, higher applied pressure of $2.9 \mathrm{MPa}$ for the DB 7475 had no positive effect on the bond strengths. Instead, the bonding temperatures of 500 and $550^{\circ} \mathrm{C}$ used for the $\mathrm{DB}$ specimens with the $\mathrm{Zn}$ interlayer may have been too high, since $\mathrm{Zn}$ undergoes a phase change at $385^{\circ} \mathrm{C}$ in $\mathrm{Al}$ [2] and is more susceptible to oxidation than the $\mathrm{Cu}$. In addition, as the $\mathrm{Zn}$ prematurely diffuses into the matrix, the areas that have not established an interfacial contact is exposed to an argon atmosphere with a partial pressure of oxygen. Many of the fracture surfaces were heavily oxidized.

The fracture behavior of the DB 7475 specimens with the $\mathrm{Cu}$ interlayer was significantly different from those of the DB 8090 specimens (Figure 5b). Fracture occurred predominantly intergranular in the base metal with some decohesion between the substrate and previous TLP. The grain surfaces were covered with both deep and shallow dimples. A qualitative analysis using energy dispersive spectroscopy of the fine particles in the boundaries indicated that they were rich in $\mathrm{Cr}$. Chromium is purposely added to $\mathrm{Al}$ to form $\mathrm{CrAl} 7$ dispersoids which were to function as the grain growth inhibitors. Instead, the insoluble dispersoid particles were swept before the advancing TLP and clustered near the triple points.[3] The partially undissolved TLP contained mostly Al-Cu-Zn. Zinc in 7475 may have reacted with the Cu-rich TLP to form a low temperature ternary TLP phase, creating localized liquated region at the grain boundary. The combined effects of high volume fraction of the incoherent phases acting as the microvoid initiators [18] and TLP coating the grain boundaries have contributed to the lower strengths of the DB 7475 with the $\mathrm{Cu}$ interalyer.

\section{Shear Properties of $D B 8090$ and 7475}

The shear strength of the bond was qualitatively estimated using a theoretical relation,[19] $\tau=0.6 \sigma_{L}$, where $\sigma_{L}$ is longitudinal tensile strength and listed in Table 1 . It is difficult to make a direct comparison between the present results and others due to the fact that many reported data are in the post-DB T6 condition. With the post-DB heat treatment, the $\mathrm{Cu}$-rich phases seen in the grain boundaries of the DB joints of both 8090 and 7475 should dissolve and reprecipitate in the matrix, thereby improving the joint strength. In addition, the joints are produced in vacuum with much longer time than the ones used in this work. Despite these differences, the estimated shear strengths of 120 and $105 \mathrm{MPa}$ for the $\mathrm{Cu}$ interlayer specimens of 8090 and 7475, respectively, are comparable to the results reported by Dunford and Partridge,[6] Pilling and Ridley, [8] and Kennedy.[9] A commercially pure $\mathrm{Al}$ with the $\mathrm{Cu}$ interlayer exhibited a maximum shear strength value of $\sim 50 \mathrm{MPa}$ after $60 \mathrm{~min}$ at $550^{\circ} \mathrm{C}$ under $3 \mathrm{MPa}$ pressure in vacuum; a low strength was attributed to $\mathrm{Al}_{7} \mathrm{Cu}_{2} \mathrm{Fe}$ particles found on the bond interface.[14] The estimated shear strengths of the $\mathrm{Zn}$ electroplated specimens of 8090 (58 MPa) are much lower than those of the Zn physical vapor deposited specimens of 8090.[2] However, for aircraft structures, the actual shear strength requirements of the bonds are generally on the order of 10-20 MPa, and the present results satisfied the requirements. The greater importance for the bond property is its resistance to peeling, particularly during the SPF process.[8]

The diffusion bonding of $95 \mathrm{Zn}-5 \mathrm{Al}$ clad SPF 7475 in an argon atmosphere has not been as successful. The joints were produced using a static pressure of $1.2 \mathrm{MPa}(175 \mathrm{psi})$ at $515^{\circ} \mathrm{C}$ for 60 min. The shear strength of $10 \mathrm{MPa}$ was obtained. The corresponding fracture surface showed very limited shear-ductile tearing (Figure 6), while oxidation continued to be a problem. Although $\mathrm{Zn}$ appeared as an ideal choice for an interlayer since it forms a low meiting TLP and has an excellent metallurgical compatibility with $\mathrm{Al}$, however, the $\mathrm{DB}$ of 7475 with the $\mathrm{Zn}$ interlayer continues to be unsuccessful. A further study is needed to better understand the effect of $\mathrm{Zn}$ on diffusion bonding of $\mathrm{Al}$ alloys. 


\section{Conclusions}

Diffusion bonding of aluminum alloys has been successfully demonstrated using the production-feasible diffusion bonding condition. The effect of surface chemistry on the DB properties of the aluminum alloys, 8090 and 7475, was evaluated for both interlayered and bare surfaces. Two interlayer elements, copper and zinc, affected each alloy differently. With the same interlayer thickness and bonding parameters, the tensile properties of the copper interlayer specimens of 8090 and 7475 were found to be substantially better than those of the bare surface and zinc interlayer specimens. For the copper interlayer specimens of 8090 and 7475 , the tensile strengths of 200 and $175 \mathrm{MPa}$ were obtained, respectively. For the zinc interlayer specimens, the advantages of using a low temperature transient liquid phase bonding were not observed. A further study is needed to better understand the effect of $\mathrm{Zn}$ on the diffusion bonding of $\mathrm{Al}$ alloys.

\section{Acknowledgement}

The author would like to thank T.G. Nieh for his technical advice, and R.C. Lum for our diffusion bonding apparatus and for producing and testing the diffusion bonds. Work performed under the auspices of the U.S. Department of Energy by the Lawrence Livermore National Laboratory under Contract W-7405-Eng-48 through LDRD, Engineering.

\section{References}

1. E.D. Weisert and G.W. Stacher, "Concurrent Superplastic Forming and Diffusion Bonding of Titanium, "in Superplastic Forming of Structural Alloys, eds. N.E. Paton and C.H. Hamilton, TMS-AIME, Warrendale, PA, 1982, pp. 273-289.

2. N. Ridley and D.W. Livesey, "Diffusion Bonding of Superplastic Al-Li (8090) using a Zinc Interlayer," in Aluminum Lithium, eds. M. Peters and P.J. Winkler, DGM Informationsgesellschaft, Verlag, 1992, pp. 1063-1068.

3. D.V. Dunford, C.J. Gilmore, and P.G. Partridge, "Transient Liquid Phase Diffusion Bonding of 8090 Al-Li Alloy", Aluminum Lithium, eds. M. Peters and P.J. Winkler, DGM Informationsgesellschaft, Verlag, 1992, pp. 1057-1062.

4 P.J. Winkler, T. Heinrich, R. Keyte, and R.A. Ricks, "Bonding and Superplastic Forming of Al-Li Alloy AA8090 for Commercial Applications", Aluminum Lithium, eds. M. Peters and P.J. Winkler, DGM Informationsgesellschaft, Verlag, 1992, pp. 1069-1074.

5. J.E. Allison and G.S. Cole, "Metal-Matrix Composites in the Automotive Industry: Opportunities and Challenges", JOM , 1993, pp. 19-24.

6. D.V. Dunford and P.G. Partridge, "Overview: Diffusion Bonding of Al-Li alloys", Mater. Sci Tech., 8, 1992, pp. 385-398.

7 A.J. Shakesheff, D.S. McDarmaid and P.J. Gregson, "Effects of Cooling Rte and Copper Content on the Properties of Al-Li-Cu-Mg-Zr Alloy 8090", Mater. Letters, 7, 1989, pp. 353-358.

8. J. Pilling and N. Ridley, "Solid State Bonding of Superplactiic AA 7475", Mater. Sci. Tech., 3, 1987, pp. 353-359.

9. J. Kennedy, "Diffusion Bonding and Superplastic Forming of 7475 Aluminum Alloy", Superplasticity and Superplastic Forming, eds. C.H. Hamilton and N.E. Paton, TMS, Warrendale, PA,1988, pp. 523-527.

10. E.R. Maddrell and E.R. Wallach, "Recent Trends in Welding Science and Technology", ASM Int'l, Metals Park, OH, 1990, p. 540.

11. A.J. Sunwoo, J.W. Morris, Jr. and G.K. Lucey, Jr., "Effect of Surface Condition on the Solderability of Pre-tinned Cu Sheet", J. Elect. Mater., 21, 1992, pp 549-557.

12. R.M. German, Liquid Phase Sintering, Plenum Press, New York, 1985, pp. 101-122.

13. H.K. Hardy and J.M. Silcock, "The Phase Sections at $500^{\circ}$ and $350^{\circ} \mathrm{C}$ of Al-rich Al-Cu-Li Alloys", J. Insti. Metals, 84, 1955-56, pp.423-428.

14. R.S. Bushby and V.D. Scott, "Liquid Phase Bonding of $\mathrm{Al}$ and $\mathrm{Al} / \mathrm{Nicalon}$ Momposite using Cu Interlayers", Mater. Sci.Tech., 9, 1993, pp. 417-423. 
15. H. Kokawa, C.H. Lee, and T.H. North, "Effect of Grain Boundaries on Isothermal Solidification during Transient Liquid Phase Brazing", Metall. Trans. A, 22A, 1991, pp. 1627-1631.

16. L.F. Mondolfo, Aluminum Alloys: Structure and Properties, Butterworth's, LondonBoston, 1976, pp. 482-3.

17. D.H. Shin, K.S. Kim, D.W. Kum, and S.W. Nam, "New A.spects on the Superplasticity of Fine-Grained 7475 Al Alloys", Metall. Trans. A, 21A, 1990, pp. 2729-2737.

18. M.E. Fine, "Stability and Coarsening of Dispersoids in Al Alloys", Dispersion Strengthened Al Alloys, eds. Y-W. Kim, and W.M. Griffith, TMS, Warrendal, PA, 1988, pp. 103-121.

19. ASM, "Source Book on Selection and Fabrication of Al Alloys", ASM Int'1, Metals Park, OH, 1978, p. 1. 
Table 1. Tensile and estimated shear strengths of diffusion bonded 8090 and $7475 \mathrm{Al}$ alloys.

\begin{tabular}{|l|c|c|}
\hline & $\begin{array}{c}\text { Fracture Strength } \\
\mathrm{MPa}\end{array}$ & $\begin{array}{c}\text { Estimated Shear Strength } \\
\mathrm{MPa}\end{array}$ \\
\hline 8090 base metal & $395 \pm 20$ & 223 \\
\hline Cu Interlayer 8090 & $200 \pm 7$ & 120 \\
\hline $\mathrm{Zn}$ Interlayer 8090 & $96.5 \pm 10$ & 58 \\
\hline Cu interlayer 7475 & $175 \pm 8$ & 105 \\
\hline $\mathrm{Zn}$ interlayer 7475 & - & - \\
\hline
\end{tabular}


Figure Captions

Figure 1. Optical micrographys of $\mathrm{Al}$ alloys shown in three orientations: (a) 8090; (b) 7475.

Figure 2. SEM fracture surface of diffusion bonded 8090 without an interlayer, showing the dimples formed by previously present $\mathrm{Li}-\mathrm{Al}$ spinel particles on the oxided surface.

Figure 3. Cross-sctions of diffusion bonded 8090 joints showing the effect of the transient liquid phase bonding: (a) with the $\mathrm{Cu}$ interlayer; (b) with the $\mathrm{Zn}$ interlayer. The interface is indicated by the arrows.

Figure 4. SEM fracture surfaces of diffusion bonded 8090 joints: (a) with the Cu interlayer, (b) with the $\mathrm{Zn}$ interlayer.

Figure 5. Diffusion bonded 7475 joint with the Cu interlayer: (a) cross-section; (b) fracture surface. The interface is indicated by the arrows.

Figure 6. SEM fracture surface of diffusion bonded SPF 7475 joint with the Zn interlayer, tested in shear. 

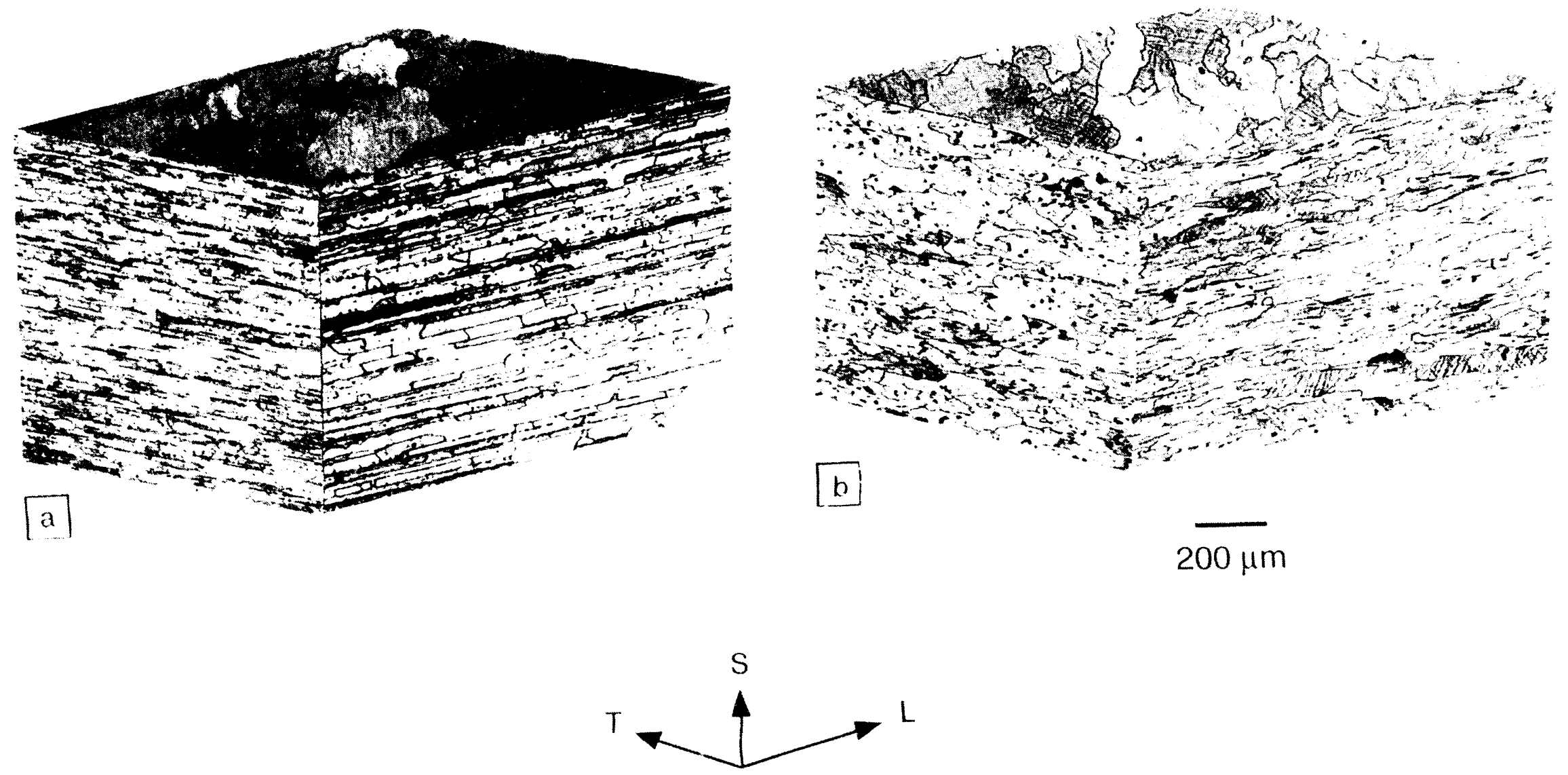


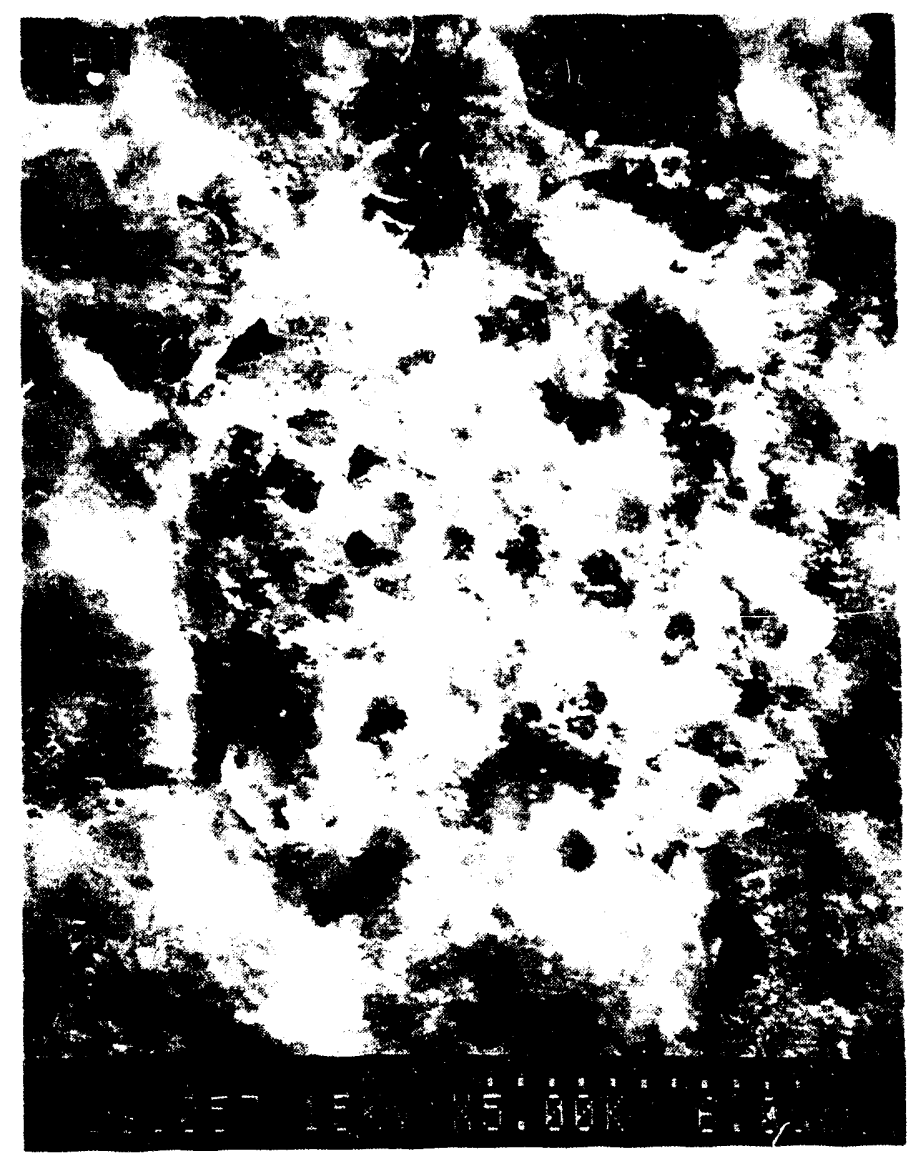



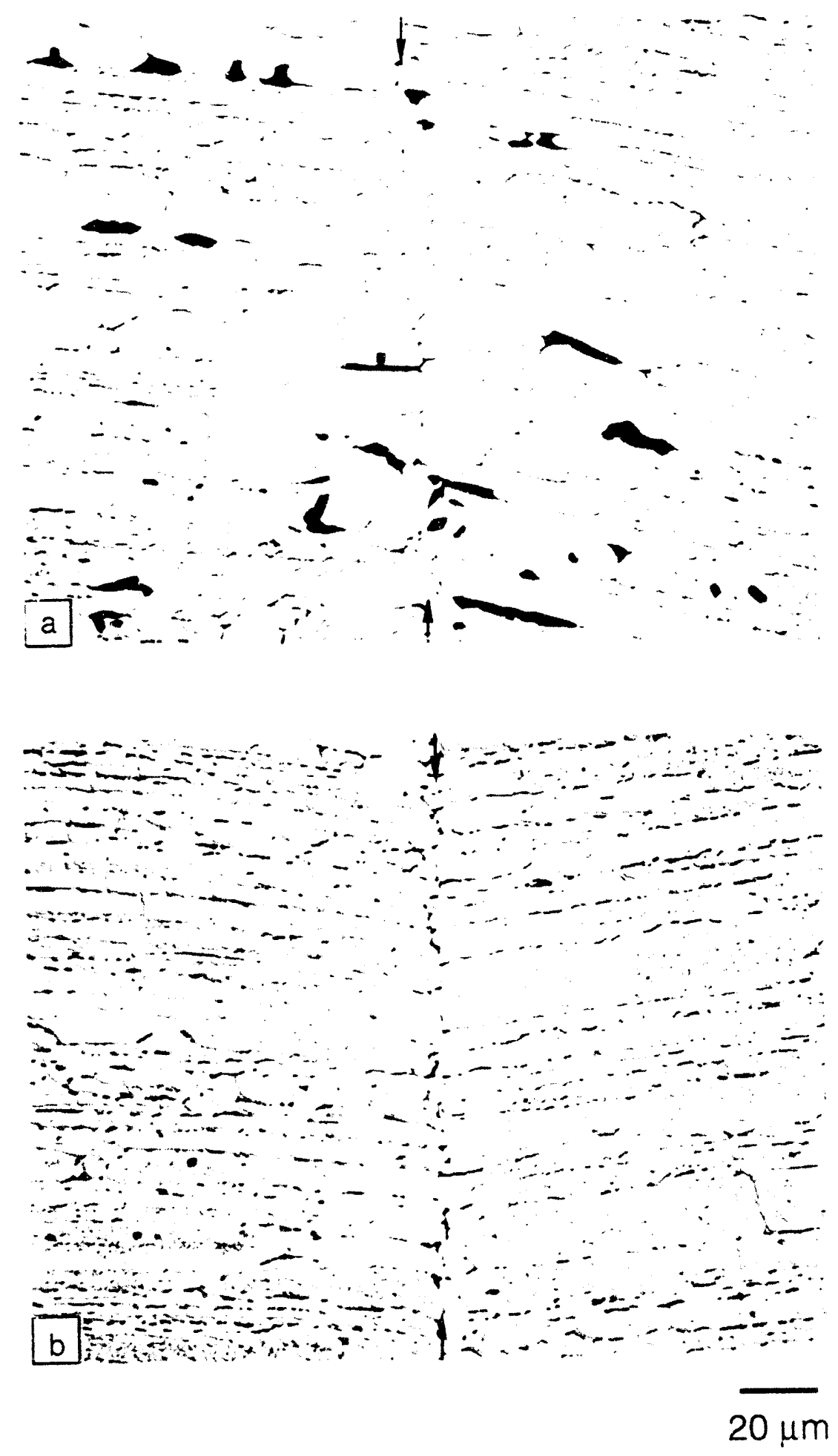

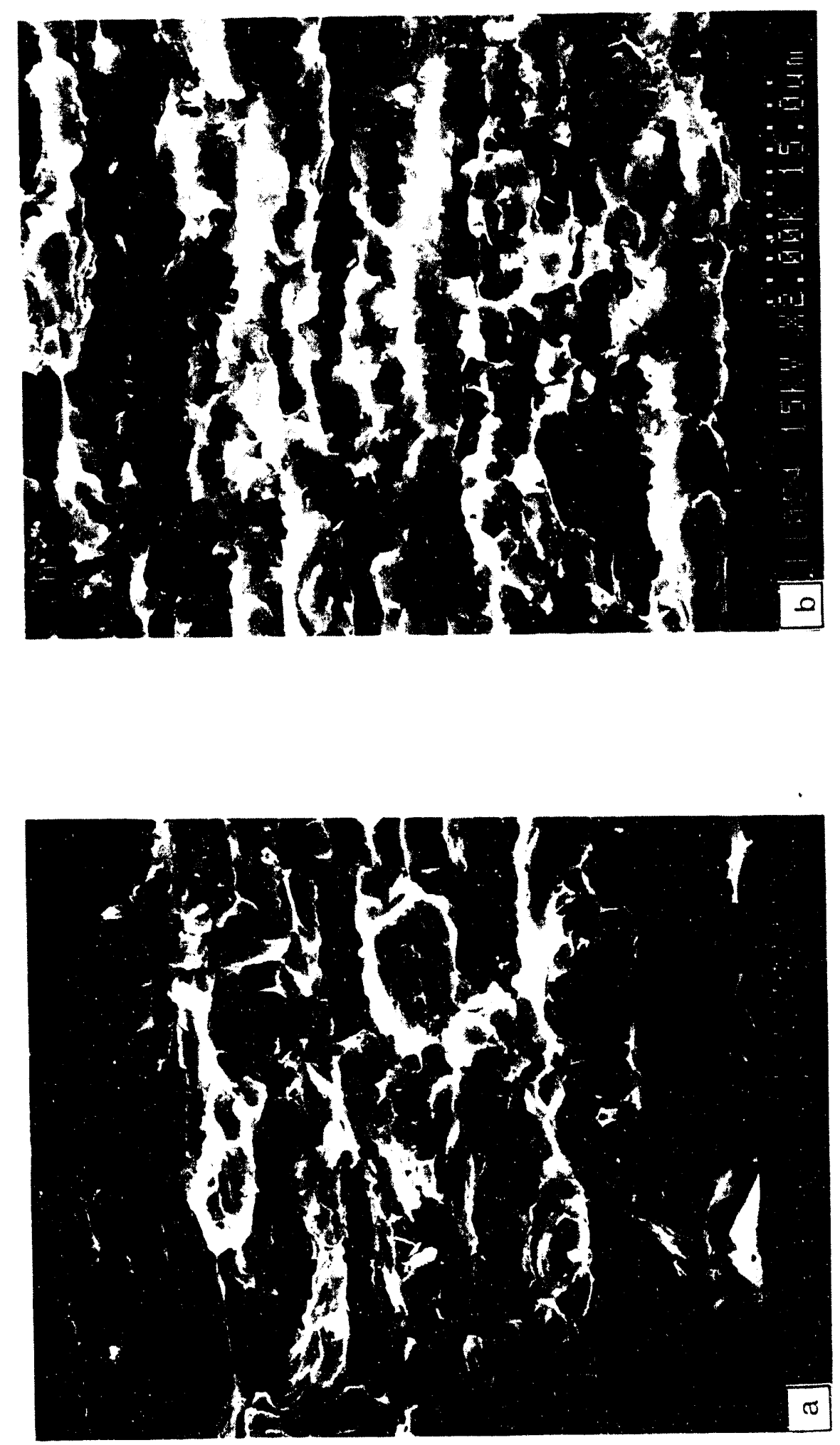

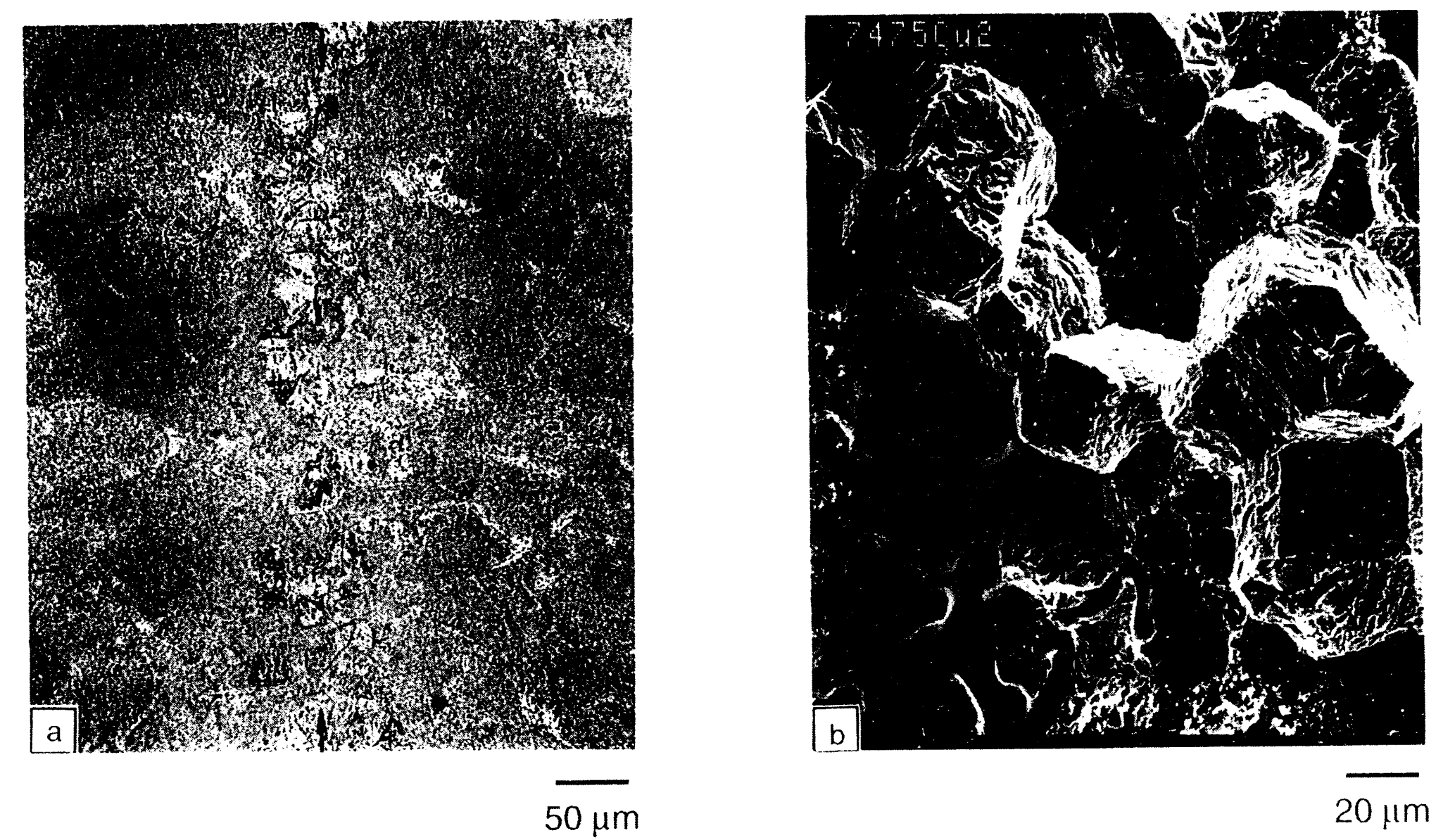


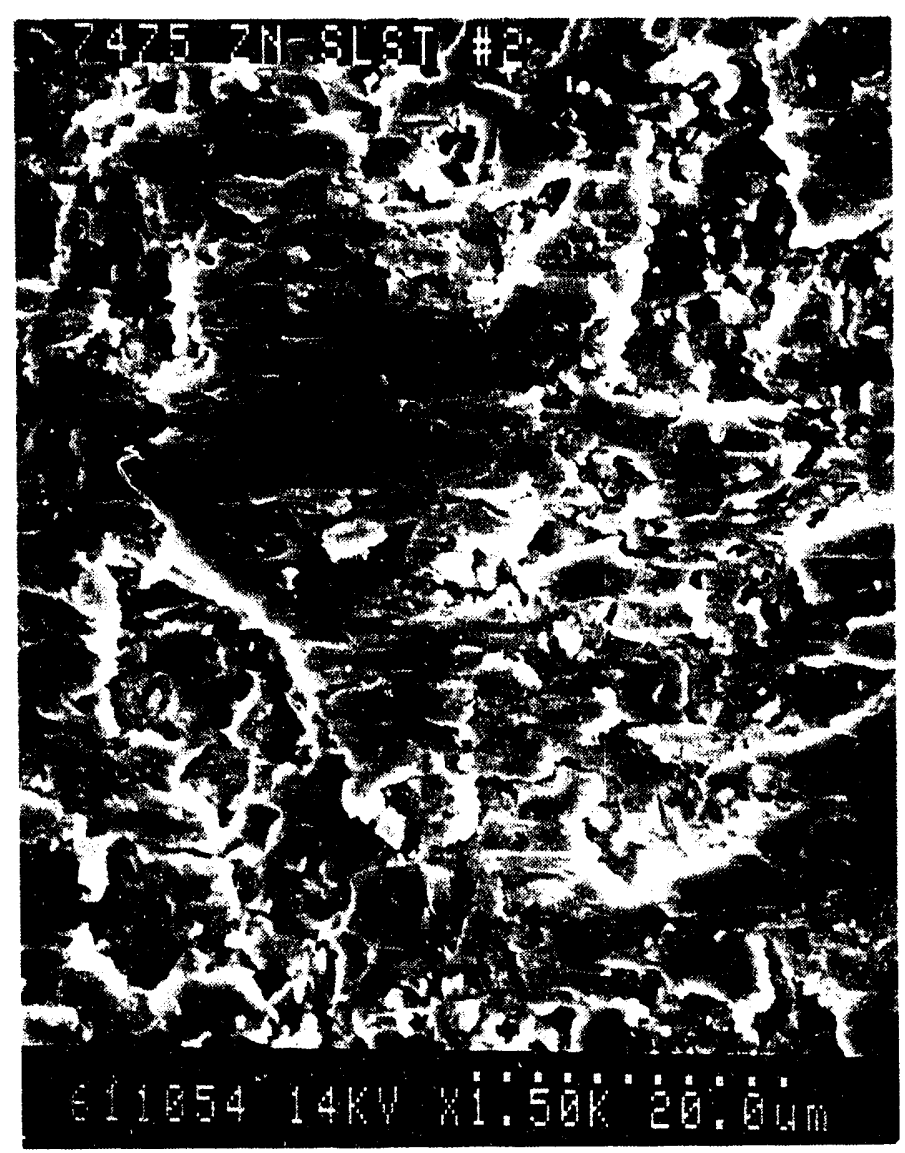



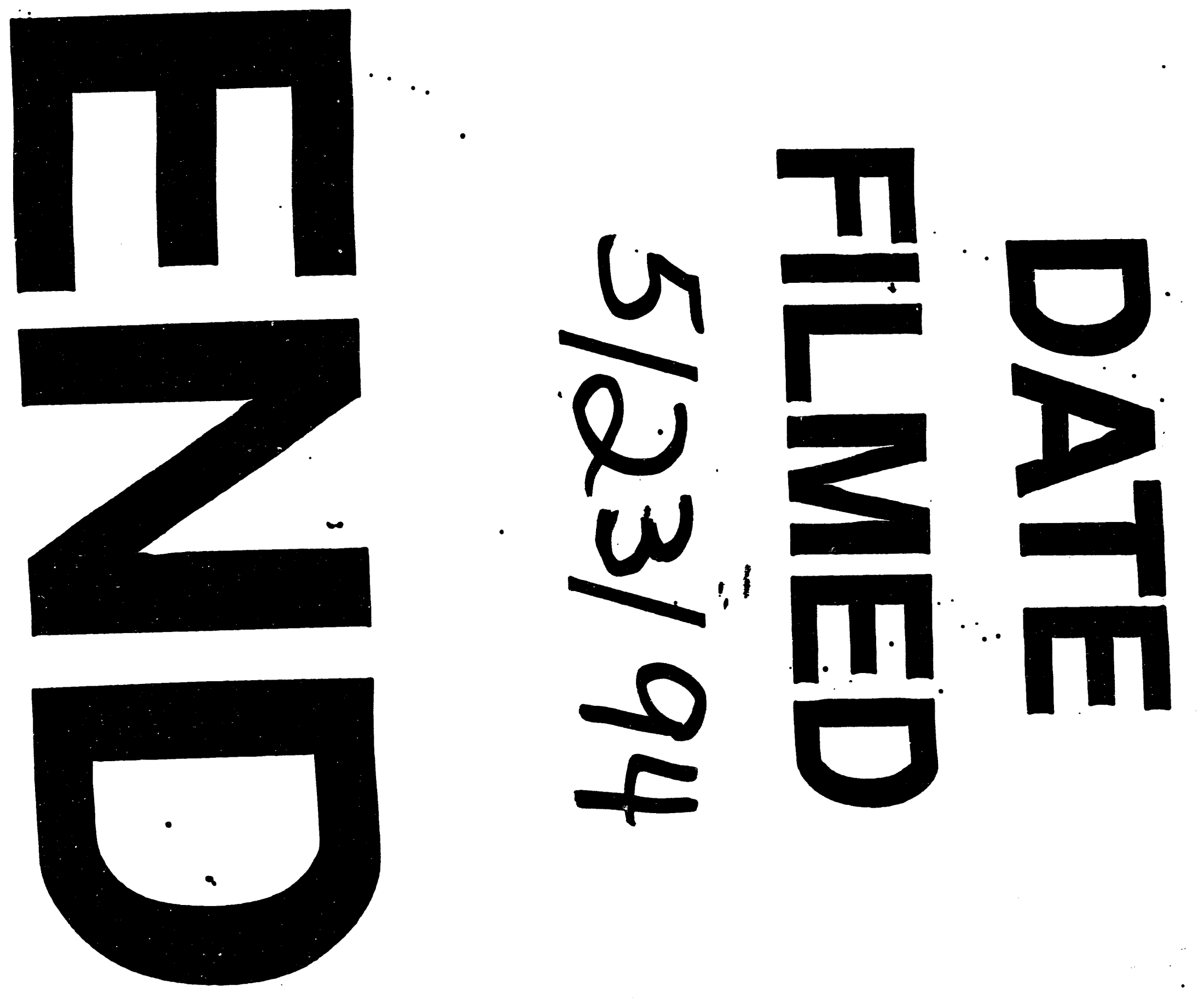


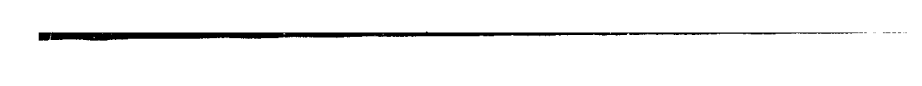

